\title{
Serum Level Of Osteopontin [Opn] in Patients with Uremic Pruritus Undergoing Hemodialysis
} A.I.El-Taweel ${ }^{1}$, A.I.Mustafa ${ }^{1}$, A.E.Mansour ${ }^{2}$, R.A.Khashba ${ }^{3}$ and S.K.Elbardan ${ }^{1}$

${ }^{1}$ Dermatology, Venereology and Andrology Dept., Faculty of Medicine, Benha Univ, Benha, Egypt

${ }^{2}$ Internal Medicin Dept., Faculty of Medicine, Benha Univ, Benha, Egypt

${ }^{3}$ Clinical and Chemical Pathology Dept., Faculty of Medicine, Benha Univ, Egypt

E-Mail: dr.saraelbardan@gmail.com

\begin{abstract}
Uremic pruritus is a common and intractable symptom in patients on chronic hemodialysis. It causes serious discomfort and skin damage, negatively affects the quality of life, and may be associated with sleep disturbance, inflammation, and higher mortality. The aim of the present study was to assess serum level of osteopontin [OPN] in patients with uremic pruritus undergoing hemodialysis and evaluation of its clinical significance and its role in the pathogenesis of Uremic Pruritis. This is a case control study that was conducted on 80 patients with end stage renal disease undergoing hemodialysis; 40 of them were suffering from uremic pruritus [Group A] and 40 patients were not suffering from it [Group B]. All patients were recruited from the hemodialysis unit of Benha University Hospital between May 2017 and July 2018, All studied subjects were tested for serum level of Osteopontin[Opn] in both patients groups using an ELISA technique, the results of the study revealed that OPN showed $95 \%$ sensitivity and $90 \%$ specificity in predicting pruritus in CKD patients undergoing hemodialysis when the cut off value $50 \mathrm{pg} / \mathrm{ml}$. Osteopontin [OPN] may play a role in the pathogenesis of uremic pruritus and can be used as a sensitive biomarker in predicting UP in chronic kidney disease patients undergoing hemodialysis.
\end{abstract}

Keywords: Osteopontin, Case Control, Hemodialysis, Uremic Pruritus.

\section{Introduction}

Uremic pruritus will be An regular Furthermore immovable manifestation clinched alongside patients with respect to incessant hemodialysis [1].

It makes not kidding uneasiness and skin damage, negatively influences the personal satisfaction about life, and might make connected with rest disturbance, inflammation, What's more higher mortal sin [2].

Those pathophysiology about uremic pruritus is mind boggling. Past investigations have demonstrated that xerosis, divalent ions, calcium-phosphate product, Creactive protein, hepatitis, hyperparathyroidism, resistant derangement, Furthermore opioid framework rotation might make connected with uremic pruritus [3].

Osteopontin , otherwise called discharged phosphoprotein 1 [SPP 1], $44 \mathrm{kDa}$ bone phosphoprotein, sialoprotein 1, 2ar, uropontin, Also punctual Tlymphocyte activation-1 [Eta-1] is An discharged matricellular protein that might have been initial recognized done 1985 by Heingard et al. Concerning illustration sialoprotein determined starting with cow-like bone grid [5].

Extreme cutaneous calcification develops basically On patients for end-stage renal illness [ESRD]. Those pathogenesis is at present unknown, which might demonstrate those different terminology: calciphylaxis, calcific uremic arteriopathy alternately azotemic arteriopathy, calcifying panniculitis, metastatic calcinosis cutis [CC], also how. Investigations need indicated that vascular calcification may be a dynamic and directed methodology both in the setting for atherosclerotic plaque arrangement What's more On Monckeberg sclerosis for calcium affidavit in the vascular networking layer. It happens basically due to the conversion for smooth muscle cell vascular cells, alternately myofibroblasts, under osteoblastlike phones that express practically of the noncollagenous bone grid proteins, for example, basic phosphatase, osteopontin, osteonectin, bone sialoprotein, Furthermore bone morphometric proteins. This wonder may happen through the actuation for Msx2-signaling that pushes both those osteogenic separation for vascular units and the regulation about circle osteopontin levels [6].

\section{Subjects and methods \\ 2.1 Type of study}

The present study was conducted as a case -control study.

\subsection{Study Population}

This study was conducted on 80 patients with end stage renal disease undergoing hemodialysis; 40 of them were suffering from uremic pruritus [Group A] and 40 patients were not suffering from it [Group B]. All patients were recruited from the hemodialysis unit of Benha University Hospital between May 2017 and July 2018.

\subsection{Ethical Considerations}

The study was approved by the local ethics committee on research involving human subjects of Benha Faculty of Medicine. Informed consents were taken from all participants before taking any data or doing any laboratory investigations.

\subsection{Inclusion criteria}

Patients on regular HD three times weekly and suffering from uremic pruritus.

\subsection{Exclusion criteria}

Any patient was excluded if he/she had:

Systemic pruritic diseases such as hepatic disease and allergic diseases.

\subsection{Methods}

All patients were subjected to the following: 


\section{1- History}

A. Personal history: name, age, sex, weight, residence, occupation and special habits of medical importance.

B. History of renal disease: Onset, course and duration of renal failure, history of underlying diseases [DM, hypertension or SLE], medications and duration of HD.

C. Pruritus history :

(A) Estimation of serum level of Osteopontin

All studied subjects were tested for serum level of Osteopontin[Opn] in both patients groups using an ELISA technique.

- Sampling: Three $\mathrm{ml}$ venous blood was collected from each subject under Complete aseptic technique after 6-8 hours fasting by clean venipuncture using disposable plastic syringe and placed on plain tube [without anticoagulant] for serum separation. The tube was left at room temperature for 30 minutes till coagulation, and then was centrifuged [at $1500 \mathrm{rpm}$ for 15 minutes].The resultant serum was stored at $20^{\circ} \mathrm{C}$ for further testing.

- Opn : A double-antibody sandwich ELISA [Enzyme Linked Immune Sorbent Assay] was used to detect serum level of Opn using a commercial Human [Opn ] ELISA Kit .
- Assay principle: The kit uses a double-antibody Sandwich enzyme-linked immunosorbent assay [ ELISA ] to assay the level of osteoponin in samples. Add Osteopontin [Opn] to monoclonal antibody Enzyme well which is pre-coated with Osteopontin [Opn] monoclonal antibody, incubation ;then , add Osteopontin [Opn] antibodies labeled with biotin , and combined with Streptavidin-HRP to form immune complex.

\subsection{Statistical analysis}

All data were analyzed using SPSS 20.0 for windows [SPSS Inc., Chicago, Illinois, USA], MedCalc Statistical Software version 15.8 [MedCalc Software bvba, Ostend, Belgium; https://www.medcalc.org; 2015].

\section{Results}

After application of the exclusion criteria; the total number of patients in the study was 80 patients with ESRD undergoing hemodialysis; 40 of them were suffering from uremic pruritus [Group A] and 40 patients were not suffering from it [Group B].

The mean serum level of OPN was significantly higher in group [A] than group [B] patients [p 0.001] as shown in Table (1).

Table (1)Comparison between the studied groups according to serum level of OPN

\begin{tabular}{|c|c|c|c|c|c|c|}
\hline & $\begin{array}{l}\text { Group } \\
{[n=40]}\end{array}$ & $\mathbf{A}$ & $\begin{array}{l}\text { Group } \\
{[n=40]}\end{array}$ & B & $\mathbf{U}$ & $\mathbf{P}$ \\
\hline \multicolumn{7}{|l|}{ OPN [pg/ml] } \\
\hline Range. & $22.6-110.4$ & & $36.1-50.1$ & & & \\
\hline Mean \pm SD & $110.2 \pm 81.19$ & & $46.2 \pm 12.5$ & & $4.000^{*}$ & $0.001^{*}$ \\
\hline
\end{tabular}

\section{Discussion}

Pruritus clinched alongside patients for propelled kidney disappointment alternately Around patients ahead dialysis camwood remain calm incapacitating influencing sleep, meddling with work, possibly bargaining caliber about an aggregation Furthermore might be whichever summed up or confined. It is transmitted centrally from the outskirts by those unmyeli- nated, large, gradually conductive c's fibers [8].

Osteopontin [OPN] may be a matricellular protein that mediates different living capacities. OPN will be included Previously, ordinary physiological forms and is embroiled in the pathogenesis of a mixture of illness states, including atherosclerosis, glomerulonephritis, cancer, Furthermore a few unending incendiary illnesses. Through associations with a few integrins, OPN mediates cell migration, adhesion, Furthermore survival On a significant number Mobile sorts. [10].

The point of the display examine might have been should evaluate serum level for osteopontin [opn] for patients for uremic pruritus undergoing hemodialysis and assessment from claiming its clinical importance.

The exhibit examine included 80 patients for limit phase renal ailment undergoing hemodialysis; 40 for them torment from uremic pruritus [Group An] Furthermore 40 patients not suffice from it [Group B]. All patients were chose from the hemodialysis unit from claiming Benha college healing centers.

There might have been no critical Contrast amidst the two aggregations viewing the sex. Effects of the available investigation might have been in contradiction with outcomes of the consider led Toward [11] who demonstrated that male sexual orientation might have been a paramount component to Creating extreme pruritus. However, [12] discovered a higher pervasiveness about uremic pruritus for females.

There were no noteworthy companionship found the middle of period Also pruritus clinched alongside our consider. Outcomes of the worth of effort might have been in contradiction for outcomes of the study led Toward [13] who accounted a huge companionship between pruritus What's more age; agdistis more youthful over 30 quite some time might have been connected with an easier danger for pruritus.

In this contemplate those serum calcium Furthermore phosphorus hint at a no huge On uremic pruritus patients assembly more than those control aggregation. 
In contradiction with our results, the serum phosphorus levels to Bleyer's investigation were All the more raised On uremic pruritus patients, Be that didn't scope Factual essentialness [17].

Clinched alongside our consider the serum level of Osteopontin [OPN] there might have been measurable critical Contrast the middle of the two mulled over Assemblies viewing OPN there might have been a Exceptionally critical build for patients more than those control gathering.

In understanding for our study, [18] contemplate those dermatological infection for patients with $\mathrm{CKD}$, they found that the level for osteopontin expand to patients for uremic pruritus. The expanded outflow about osteogenic markers that actuate calcification. Osteopontin, communicated Eventually Tom's perusing vascular smooth muscle cell cells[VSMC], will be expanded to patients for CUA lesions. Also, bone morphogenic protein 4 [BNP4], typically included for bone development, might have been found in atherosclerotic lesions Also will be upregulated Previously, periarterial dermal units for CUA.

Osteopontin affidavit need also been embroiled in the calcification procedure of the considerate cutaneous tumor called pilomatrixoma. It need also been connected with those mineralization for dermal versatile fibers On patients with pseudoxanthoma elasticum. [22].

\section{Conclusion}

Osteopontin [OPN] might assume a part in the pathogenesis of uremic pruritus Also camwood make utilized Likewise a touchy biomarker Previously, foreseeing dependent upon over constant kidney sickness patients undergoing hemodialysis.

\section{References}

[1] V.S.Mathur, J.Lindberg, M.Germain, A longitudinal study of uremic pruritus in hemodialysis patients. Clin.J.Am.Soc. Nephrol, Vol.5, PP.1410-1419,2010.

[2] M.I.Duque, S.Thevarajah, Y.H.Chan, Uremic pruritus is associated with higher $\mathrm{kt} / \mathrm{V}$ and serum calcium concentration. Clin.Nephrol, Vol. 66, PP. 184 91,2006.

[3] M.J.Ko and H.Y.Chen, Uremic pruritus, dialysis adequacy, and metabolic profiles in hemodialysis patients: a prospective 5-year cohortstudy. P.L.o.S.One,Vol.8,PP.71404-09,2011.

[4] A.Franzen and D.Heinegard, Isolation and characterization of two sialoproteins present only in bone calcified matrix. Biochem. J, Vol.232, PP.715724,1985 .

[5] D.Rivet and L.Celeste, Medial artery calcification in ESRD patients is associated with deposition of bone matrix proteins. Kid Int ,Vol.8,PP.61638- 647,2006.

[6] I.Narita, B.Alchi, K.Omori, Etiology and prognostic significance of severe uremic pruritus in chronic hemodialysis patients. Kid. Int, Vol.69,PP.1626$1632,2006$.

[7] S.A. Lund, and C. Giachelli, The role of osteopontin in inflammatory processes. J. Cell Commun. Signal, Vol.3,PP.311-322,2009.

[8] O.Kentaro, I.Ikuo, A.Haruki, Risk factors for uremic pruritus in long-term hemodialysis patients. J. Jpn. Soc.Dial.Ther, Vol.12,PP.1469-77,2001.

[9] N.R. Dar, and A. Akhter, Clinical characteristics of uremic pruritus in patients undergoing haemodialysis. J. Coll. Phys. Surg. Pak,Vol. 16(2), PP.94-96,2006.

[10] K.Omori, Etiology and prognostic significance of severe uremic pruritus in chronic hemodialysis patients. Kid. Int,Vol.69,PP.1626-32,2006.

[11] A.J.Bleyer , M.Chol , B.Igwemezie, A case control study of proximal calciphylaxis. Am. J. Kid. Dis, Vol.32,PP.376-383,1998.

[12] M.B.Contri, F.Boraldi, F.Taparelli, Matrix proteins with high affinity for calcium ions are associated with mineralization within the elastic fibers of pseudoxanthoma elasticum dermis. Am.J.Pathol,Vol.148,PP.569-577,1996. 